\title{
(175)
}

\section{Preliminary Attempts to Conserve Bryophytes in Lowland Forests of Sri Lanka: A Case Study at Yagirala Forest Reserve}

\author{
M.A.B.N. Gunarathne ${ }^{1}$, I.U. Kariyawasam ${ }^{1 *}$, S.C.K. Rubasinghe ${ }^{2}$ \\ ${ }^{1}$ Department of Botany, University of Sri Jayewardenepura, Sri Lanka \\ ${ }^{2}$ Department of Botany, University of Peradeniya, Sri Lanka \\ *isurufasi@gmail.com
}

\begin{abstract}
Bryophytes were the first dwellers of the land plant history and play a vital role in the dynamics of the forest ecosystems such as water flow regulation and nutrient cycling. Considerable efforts on surveying and taxonomic studies of bryoflora in Sri Lanka was done in the early and mid-19th century by foreign scientists and there is a huge gap for several decades till late 1990s and no proper systematic survey of bryoflora in lowland forests in Sri Lanka has been carried out in the recent past. Sri Lanka is a biodiversity hotspot and it has a rich and diverse tropical bryoflora in the lowland and highland natural wet -moist forests. Yagirala forest reserve is a lowland tropical rainforest situated in the low country wet zone. Many floristic researches on angiosperms have been carried out but there is no systematic survey has been carried out to study the cryptogamic plants in the forest. Hence this is the first attempt to study and identify distribution of the bryoflora at Yagirala forest reserve. The bryophyte diversity in three main ecosystems in the forest including the primary forest, secondary forest and the forest associated with the Pinus plantation was studied. Ten (10) different families of mosses (including 12 genera, 16 species), Six (06) families of leafy liverworts (including 12 genera, 14 species) and 03 families of simple thalloid liverworts (including 03 genera, 03 species) were found. All species records were mapped and seemed to be new species records to Sri Lanka. DNA samples were collected for further barcoding studies and voucher specimens were prepared. A comparison of the species diversity in each major habitat type was studied and some anthropogenic and natural threats to the native bryoflora in the forest were studied. Further intensive research work is needed to prepare a complete checklist of bryoflora in the Yagirala Forest reserve and the final output of the project will be developing a user-friendly pocket guide to study the common bryophytes in the forest and this will open a novel avenue to initiate the conservation and IUCN redlisting of lowland bryoflora in Sri Lanka.
\end{abstract}

Keywords: Bryophytes, Preliminary survey, Yagirala Forest Reserve, Conservation 